\title{
Smokers respond to anti-tobacco mass media campaigns in NSW by calling the Quitline
}

\author{
Trish Cotter ${ }^{\mathrm{A}, \mathrm{C}}$, Donna A. Perez ${ }^{\mathrm{A}}$, \\ Anita L. Dessaix ${ }^{\mathrm{A}}$ and James F. Bishop ${ }^{\mathrm{B}}$ \\ ${ }^{\mathrm{A}}$ Cancer Prevention, Cancer Institute New South Wales

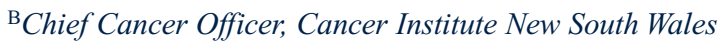 \\ ${ }^{\mathrm{C} C o r r e s p o n d i n g ~ a u t h o r . t r i s h . c o t t e r @ c a n c e r i n s t i t u t e . o r g . a u ~}$
}

\begin{abstract}
Objective: One aim of the anti-tobacco mass media campaigns in NSW is to increase the numbers of smokers calling the Quitline to seek assistance to quit. Methods: Investigation of the relationship between the weight of television advertising (Target Audience Rating Points: TARPs) and number of calls to the Quitline. Results: There is a high correlation between weekly Quitline calls and TARPs. Conclusions: Anti-tobacco mass media campaign advertising that promotes the Quitline number encourages smokers to seek assistance to quit.
\end{abstract}

The NSW State Plan, NSW Cancer Plan and the NSW Tobacco Action Plan 2005-2009 set a target of an annual one percentage point reduction in smoking prevalence. Under these plans, the Cancer Institute NSW has the primary responsibility for the design, development and delivery of mass media campaigns that aim to influence smoking behaviours and encourage smokers to quit. ${ }^{1,2}$ Since 2004, the NSW Government has committed substantial funding to these campaigns.

In New South Wales (NSW) in 2006, smokers were the target of 32 weeks of anti-tobacco television advertising funded by the Cancer Institute NSW. In addition, at the beginning of 2006, the Commonwealth Government funded two campaigns totalling 10 weeks - the Australian Competition and Consumer Commission (ACCC) Lights and Milds Campaign and a Primer Campaign for the introduction of graphic health warnings on tobacco products. Advertisements for nicotine replacement therapy (NRT) products, funded by pharmaceutical companies, also aired throughout this period.
Telephone Quitlines providing counselling and support are effective in assisting smokers to quit. ${ }^{4}$ Previous studies have shown that smokers who call the Quitline, particularly those who use callback counselling, can increase their chances of quitting successfully.,5

The present study presents data on the relationship between anti-tobacco television advertising in 2006 and the volume of Quitline calls generated in response.

\section{Methods}

\section{Advertising campaigns}

The Cancer Institute NSW launched the first of its antitobacco mass media campaigns for 2006 on 18 April with a campaign to promote the services provided by the Quitline. This Quitline Services Campaign was followed closely by the first advertisement for the Health Warnings Campaign - Amputation, which was developed in partnership with Quit Victoria. The Health Warnings Campaign was designed to extend the meaning and personal relevance of the graphic health warnings on cigarette packs introduced in March 2006. Mouth Cancer was the second advertisement for the Health Warnings Campaign and was aired later in July and August 2006. The Pubs and Clubs Campaign, Change is in the Air, was aired, as in 2005, to coincide with the changes in legislation regarding smoking restrictions in NSW pubs and clubs in July (this campaign did not promote the Quitline number). Two campaigns previously aired in 2005 were repeated in $2006-$ Excuses and Parents. An overview of the 2006 campaigns is provided in Table 1 .

The target of the advertising was primarily adult smokers, although this varied between the campaigns. The Quitline number was shown at the end of all the advertisements to facilitate a smoker's behavioural response by calling the Quitline.

\section{Television advertising activity}

The standard advertising industry measure of television advertising weight scheduled to reach the target audience is a Target Audience Rating Point (TARP). It is an estimate based on Australian Television Audience Measurement $(\mathrm{Oz}$ TAM) and is a multiple of the percentage of the target audience reached by the campaign and the average number of times a target audience member is exposed to the 
advertising. For example, one TARP represents $1 \%$ of the target audience who have had the opportunity to see a campaign advertisement on television once. ${ }^{6,7}$

When developing a campaign, total weekly TARPs are normally the reference point. Total weekly TARPs of 200, for example, could be an aggregate of $20 \mathrm{TV}$ spots or advertising placements each generating 10 TARPs. There will be audience duplication as viewers generally see more than one ad in a week. Weekly TARPs of 200 would reach approximately $70 \%$ of a target audience 2.8 times. The more weekly TARPs, the heavier the advertising and the more repetition generated.

Weekly television performance data for Cancer Institute NSW campaigns based on actual TARPs, including bonuses (extra spots aired in addition to TARPs that are paid for), was supplied by MediaCom. Data were weighted according to the metropolitan (Sydney) and regional (Northern and Southern NSW) television market population potentials for 2006 for each campaign. A hybrid Southern NSW market, including Wollongong, Central West (Orange, Wagga and Dubbo) and Albury, was created to account for the exclusion of Canberra in the media buy. The target age group for the campaigns varied across 2006, so the TARP weighting was conducted on the basis of a fixed category at 16 years and over. The metropolitan and regional data were then aggregated to give a total NSW figure for each campaign.
The TARPs for the two Commonwealth-funded campaigns have been sourced from ACNielsen and aggregated for NSW based on unweighted data. The TARPs for the NRT product advertising are not included in this data.

\section{Quitline calls}

Quitline call data are routinely collated nationally by the Tobacco Control Research and Evaluation Program, Cancer Council South Australia through the use of Telstra Analyser as part of the monitoring of the 137848 (13QUIT) and 131848 Quitline numbers. This allows assessment of the actual number of calls, with data available on successful (calls answered) and un-successful (not answered, abandoned or busy) calls. The call data presented in the present study represent successful calls made in NSW to both Quitline numbers. The number of callers going on to use the NSW Quitline telephone counselling service is also monitored; however, it is not reported here.

To compare whether Quitline calls were correlated with TARPS, we calculated the correlated coefficient of the weekly counts of Quitline calls and weekly aggregated NSW TARPs using R8 statistical software. ${ }^{8}$

\section{Results}

Figure 1 plots the weekly aggregate TARPs for each campaign and successful calls to the Quitline for 2006. The media schedule differed across the campaigns and con-

Table 1. Overview of 2006 anti-tobacco campaigns funded by Cancer Institute NSW

\begin{tabular}{|c|c|c|c|}
\hline Campaigns 2006 & Description & Aim and target & Media \\
\hline $\begin{array}{l}\text { Quitline Services: } \\
\text { April to October } \\
\text { - flighted }\end{array}$ & $\begin{array}{l}\text { Six } 15 \text {-second advertisements featuring } \\
\text { Quitline advisers talking about several } \\
\text { topics, including planning to quit, } \\
\text { cravings, nicotine replacement therapy, } \\
\text { callbacks, previous attempts and no best } \\
\text { way to quit. }\end{array}$ & $\begin{array}{l}\text { Aims to provide smokers with an insight } \\
\text { into the Quitline and the range of } \\
\text { services and support available. } \\
\text { Target: } 18-24 \text { years }\end{array}$ & $\begin{array}{l}\text { Television } \\
\text { Radio } \\
\text { Press } \\
\text { Outdoor }\end{array}$ \\
\hline $\begin{array}{l}\text { Health Warnings: } \\
\text { May to October } \\
\text { - flighted }\end{array}$ & $\begin{array}{l}\text { Amputation - features an operation to } \\
\text { remove a leg that has gangrene. } \\
\text { Mouth Cancer - features a woman with } \\
\text { visual symptoms of mouth cancer. }\end{array}$ & $\begin{array}{l}\text { Aims to build on the graphic health } \\
\text { warnings on tobacco products and } \\
\text { increase impact when a smoker } \\
\text { purchases a tobacco product. } \\
\text { Target: } 18-24 \text { years }\end{array}$ & $\begin{array}{l}\text { Television } \\
\text { Radio } \\
\text { Press } \\
\text { Outdoor }\end{array}$ \\
\hline $\begin{array}{l}\text { Change is in the Air } \\
\text { (Pubs and Clubs): } \\
\text { June/July. Joint project } \\
\text { with NSW Health }\end{array}$ & $\begin{array}{l}\text { Features David Callan (an Irish comedian) } \\
\text { talking about smoking restrictions in } \\
\text { NSW pubs and clubs. }\end{array}$ & $\begin{array}{l}\text { Aims to increase awareness among } \\
\text { the NSW community of the new } \\
\text { changes to smoking inside licensed } \\
\text { venues. Target: } 18-39 \text { years }\end{array}$ & $\begin{array}{l}\text { Television } \\
\text { Radio } \\
\text { Press } \\
\text { Ambient }^{b}\end{array}$ \\
\hline $\begin{array}{l}\text { Excuses (Echo 1\&2): } \\
\text { May/June }\end{array}$ & $\begin{array}{l}\text { Features several scenarios of excuses } \\
\text { smokers use and the health consequences } \\
\text { of not quitting. Re-run from } 2005 \text {. }\end{array}$ & $\begin{array}{l}\text { Aims to encourage smokers to put } \\
\text { quitting on 'today's agenda' by } \\
\text { tackling the excuses for delaying } \\
\text { quitting. Target: } 25-54 \text { years }\end{array}$ & $\begin{array}{l}\text { Television } \\
\text { Press }\end{array}$ \\
\hline Parents: September & $\begin{array}{l}\text { Features a young girl talking to her father } \\
\text { who is in a hospital bed. Re-run from } 2005 .\end{array}$ & $\begin{array}{l}\text { Aims to highlight the impact of smoking } \\
\text { on the health of the smoker and also } \\
\text { on the smoker's relationship with loved } \\
\text { ones. Target: } 30-49 \text { years }\end{array}$ & $\begin{array}{l}\text { Television } \\
\text { Radio } \\
\text { Press } \\
\text { Cinema }\end{array}$ \\
\hline
\end{tabular}




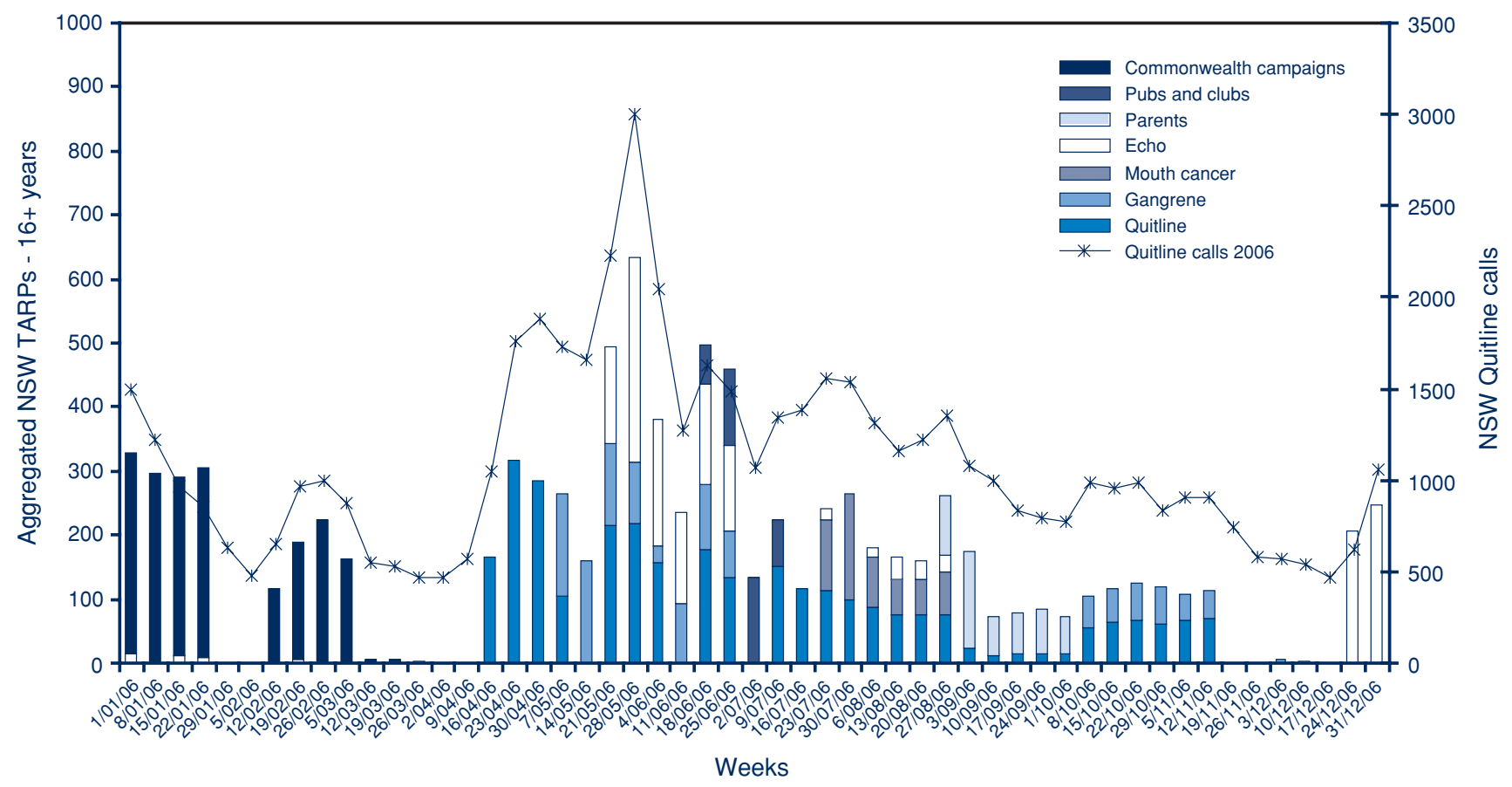

Fig. 1. Weekly target audience rating points (TARPs) for television anti-tobacco campaigns for the NSW population over the age of 16 years compared with the number of calls to the NSW Quitline in 2006

sisted of periods where there was overlap, with up to four campaigns on air in mid to late June. Over the period from April to December 2006, Quitline calls were highly correlated with TARPs (correlation coefficient, $r=0.88$; $p<0.001)$.

An average of just over 1200 calls per week were achieved over the period April to December, relative to an average of just over 190 TARPs. A decreasing trend in Quitline calls was also observed over the period July to November, corresponding with reduced TARP levels; an average of just over 1000 calls per week was achieved over this period relative to an average of just over 130 TARPs.

In 2006, the largest peak in calls occurred in May and was highest in the week that included World No Tobacco Day (31 May), with just over 3000 calls. Although there were high TARP levels, there are usually several public relations activities associated with this day. The next highest peak in calls followed the launch of the Quitline Services Campaign in April 2006, with calls increasing to 1883 after three weeks on air - more than triple the calls compared with the week before the launch.

\section{Discussion}

A significant relationship was demonstrated between Quitline calls and TARPs, similar to that found in response to the National Tobacco Campaign over the period 1997 to 1998. 7,9,10 The volume of calls to the Quitline was influenced by three main factors in 2006: the introduction of graphic warnings on packs (from March) featuring the Quitline number; public relations activities in May for
World No Tobacco Day; and television advertising weight or TARPs.

The results also indicate that low to medium TARP levels (an average of just over 130) could generate a reasonable amount of calls per week (average just over 1000). All of the campaigns appear to have played a role in generating calls.

The results presented here provide further evidence that television advertising not only promotes awareness of the Quitline number, but also leads to a call response. Increasing the number of smokers calling the Quitline is a desired outcome given that it can increase their chances of quitting successfully, ${ }^{4,5}$ However, previous studies have also shown that only a small proportion of smokers will call the Quitline for assistance to quit. ${ }^{10}$ Therefore the Quitline call response does not provide a complete picture of the community impact of anti-tobacco mass media campaigns.

\section{Conclusion}

The results indicate that promoting the Quitline through anti-tobacco mass media campaign advertising does encourage smokers to seek assistance to quit.

\section{Acknowledgment}

The authors would like to thank Arthur Hung for his assistance with the statistical analysis.

\section{References}

1. Cancer Institute New South Wales. NSW cancer plan 2007-2010. Sydney: Cancer Institute NSW, 2006. 
2. NSW Department of Health. NSW Tobacco Action Plan 2005-2009. North Sydney: NSW Department of Health, 2005.

3. Monash University. Marketing dictionary. Available at . Accessed 28 June

2007.doi:http://www.buseco.monash.edu.au/mkt/dictionary/

4. Stead LF, Perera R, Lancaster T. Telephone counselling for smoking cessation Cochrane Database of Systematic Reviews 2006; (3): CD002850.

5. Borland R, Segan CJ, Livingston PM, Owen N. The effectiveness of callback counselling for smoking cessation: a randomized trial. Addiction 2001; 96: 881-9.

doi:10.1046/j.1360-0443.2001.9668819.x

6. Donovan R, Henley N. Social marketing: principles and practice. Melbourne: IP Communications, 2003.

7. Williams $P$, Bleasdale $T$. The relationship between campaign television activity and Quitline call data. In: Hassard K, editor.
Australia's national tobacco campaign: evaluation report, volume one. Canberra: Commonwealth Department of Health and Aged Care, 1999.

8. R Development Core Team. R: a language and environment for statistical computing. Vienna: R Foundation for Statistical Computing, 2007. Available at http://www.r-project.org. Accessed 11 January 2008.

9. Tan N, Hassard K. Quitline calls and campaign television investment. In: Hassard K, editor. Australia's national tobacco campaign: evaluation report, volume two. Canberra: Commonwealth Department of Health and Aged Care, 2000.

10. Miller CL, Wakefield M, Roberts L. Uptake and effectiveness of the Australian telephone Quitline service in the context of a mass media campaign. Tob Control 2003; 12: 53-8. 